\title{
Análise das dificuldades dos alunos no componente curricular de química a partir dos conteúdos abordados no ENEM
}

\author{
Analysis of students' difficulties in the curricular component of chemistry from the contents \\ addressed in ENEM
}

Análisis de las dificultades de los estudiantes en el componente curricular de química a partir de los contenidos abordados en el ENEM

\section{Resumo}

A educação do Brasil se depara com algumas dificuldades, e estas são refletidas nos resultados das avaliações internas e externas. Estes evidenciam as dificuldades que os alunos têm em aprender e compreender os conteúdos de química. O objetivo deste trabalho é realizar uma análise das dificuldades relatadas por alunos do $3^{\circ}$ ano do Ensino Médio de uma escola pública regular, localizada no Pecém (município de São Gonçalo do Amarante - CE), em face dos conteúdos de Química abordados no Exame Nacional do Ensino Médio - ENEM. Este trabalho se caracteriza como uma pesquisa aplicada, de natureza quantitativa e caráter exploratório. Foi aplicado um questionário, com os conteúdos recorrentes no ENEM, com a finalidade de compreender em quais assuntos os alunos apresentaram mais dificuldades e a partir disto, fazer uma discussão dessas informações à luz dos teóricos ligados as principais tendências pedagógicas vigentes. Os resultados desta pesquisa demonstraram que os conteúdos que apresentaram o pior desempenho por parte dos estudantes foram: compostos orgânicos e cálculos estequiométricos, os quais necessitam de um conhecimento prévio de cálculos, além de interpretação para identificar as funções oxigenadas e entender sua nomenclatura.

Palavras-chave: Aprendizagem; Avaliações externas; Ensino médio.

\begin{abstract}
Education in Brazil faces some difficulties, and these are reflected in the results of internal and external evaluations. These results show the difficulties that students have in learning and understanding the contents of chemistry. The objective of this work is to carry out an analysis of the difficulties reported by students in the 3rd year of high school in a regular public school, located in Pecém (municipality of São Gonçalo do Amarante - CE), considering the Chemistry contents covered in the National Exam of High School - ENEM. This work is characterized as applied research, of a quantitative and exploratory nature. A questionnaire was applied, with the recurrent contents in ENEM, to understand in which subjects the students had more difficulties and based on this, to discuss this information in the light of theorists linked to the main current pedagogical trends. The results of this research showed that the contents that presented the worst performance by the students were: organic compounds and stoichiometric calculations, which require prior knowledge of calculations, as well as interpretation to identify oxygenated functions and understand their nomenclature. Keywords: External reviews; High school; Learning.
\end{abstract}

\section{Resumen}

La educación en Brasil enfrenta algunas dificultades, que se reflejan en los resultados de las evaluaciones internas y externas. Estos resultados muestran las dificultades que tienen los estudiantes para aprender y comprender los 
contenidos de la química. El objetivo de este trabajo es realizar un análisis de las dificultades reportadas por los estudiantes de 3er año de secundaria en una escuela pública regular, ubicada en Pecém (municipio de São Gonçalo do Amarante - CE), a la luz de los contenidos de Química cubiertos en el Examen Nacional de Bachillerato - ENEM. Este trabajo se caracteriza por ser una investigación aplicada, de carácter cuantitativo y exploratorio. Se aplicó un cuestionario, con los contenidos recurrentes en ENEM, con el fin de comprender en qué materias los estudiantes tenían más dificultades y, en base a ello, discutir esta información a la luz de teóricos vinculados a las principales corrientes pedagógicas actuales. Los resultados de esta investigación arrojaron que los contenidos que presentaron peor desempeño por parte de los estudiantes fueron: compuestos orgánicos y cálculos estequiométricos, que requieren conocimientos previos de cálculo, así como interpretación para identificar funciones oxigenadas y comprender su nomenclatura.

Palabras clave: Aprendiendo; Escuela secundaria; Revisiones externas.

\section{Introdução}

A educação brasileira se depara com algumas dificuldades em relação ao processo de ensino aprendizagem em Ciências da Natureza e estes são refletidos nos resultados das avaliações internas (nos indicadores de aprovação, reprovação e evasão escolar) e externas, como nas avaliações do SAEB (Sistema de Avaliação da Educação Básica) e do PISA (Programa Internacional de Avaliação de Alunos). Neste último, os estudantes brasileiros obtiveram média inferior aos alunos dos países da OCDE - Organização para a Cooperação e Desenvolvimento Econômico para a área de Ciências (Pizarro \& Lopes Junior, 2017). Estas informações são preocupantes, e remetem as dificuldades que estes alunos têm em aprender e compreender os conteúdos de Ciências, ressaltando a disciplina de Química, pintando um quadro desmotivador para o ensino deste componente curricular. Segundo Rocha e Vasconcelos (2016), tal ensino segue ainda de maneira tradicional, de forma descontextualizada e não interdisciplinar, gerando nos alunos um grande desinteresse pela matéria, bem como dificuldades em aprender e relacionar o conteúdo estudado ao cotidiano..

O Enem (Exame Nacional do Ensino Médio), considerado uma avaliação externa, é utilizado como vestibular por várias instituições do ensino superior, tendo como papel avaliar o desempenho dos concludentes do ensino médio. Conforme os resultados divulgados pelo Instituto Nacional de Estudos e Pesquisas Educacionais Anísio Teixeira - INEP, das quatro áreas avaliadas, as ciências da natureza apresentaram uma redução na nota média durante as três edições anteriores. No ano de 2017, sua nota correspondeu a 510,6; no ano seguinte, 2018, alcançou 493,8. Analisando esses dois anos, ocorreu uma redução expressiva, com uma diferença de 16,8 pontos entre as notas. No ano de 2019 atingiu a nota de 477,8, comparando essa com a de 2018, foi identificada uma redução, com a diferença de 16 pontos (G1, 2020).

Este panorama transmite uma inquietação por parte de todos que estão envolvidos com a educação do Brasil. Pode-se estabelecer algumas hipóteses que contribuem em maior ou menor grau para a realidade apresentada, a saber: alunos que não se sentem motivados e nem compreendem a necessidade do ensino da química, como também apresentam dificuldades em conteúdos básicos, como cálculos e interpretação (Belo et al., 2019); professores ministrando aulas sem possuir a devida formação e; a escassa valorização social do profissional da educação, sendo representada pelo valor do salário atribuído ao mesmo (Saviani, 2011); instituições carentes de estrutura e tecnologia mantendo constantemente a filosofia do racionamento de recursos devido à dificuldade de consegui-lo (Figueiredo et al., 2015), entre outros, podem ser considerados alguns dos fatores que contribuem para a precarização do sistema educacional brasileiro, sobretudo na esfera pública.

O surgimento do Exame Nacional do Ensino Médio (Enem) teve como proposta inicial ser um exame avaliativo de larga escala, porém com o decorrer de mais de duas décadas, sua atuação para melhorar e auxiliar a educação foi direcionado para outro foco, tornando-se o principal instrumento de ingresso dos estudantes no ensino superior do país. No ano de sua criação, em 1998, o Ministério da Educação (MEC) não imaginava que esta avaliação apresentaria um papel tão importante na vida de milhares de concludentes do ensino médio, que sonhavam em ingressar no ensino superior. Seu objetivo, para o governo federal inicialmente, era tão somente como um indicador público, sendo uma ferramenta para avaliar a qualidade do ensino médio das escolas públicas e particulares (da Silveira et al., 2015). 
Segundo o Instituto Nacional de Estudo e Pesquisa Anisio Teixeira - INEP, a primeira edição do Enem registrou 157.221 inscrições e contou com 115.575 participantes no dia 20 de agosto de 1998. A prova possuía 63 questões objetivas e uma redação dissertativa, que ocorreu em apenas um dia com duração de 5 horas. Nesta época, a prova atingiu 184 municípios brasileiros e apenas duas instituições de educação superior fizeram uso das notas. No ano seguinte, o número de instituições de educação superior que começaram a utilizar os resultados do Enem subiu, passando de 2 para 93, confirmando a credibilidade do exame a partir do aumento da quantidade de faculdades e universidades que estavam adotando como seu principal processo seletivo (Silva, 2020).

Com uma cara nova, o Enem em 2009, com 180 questões objetivas, distribuídas 45 para cada uma das quatro áreas de conhecimento (Ciências Humanas e suas Tecnologias, Ciências da Natureza e suas Tecnologias, Linguagens, Códigos e suas Tecnologias e Matemática e suas Tecnologias) com uma proposta de redação. Essa mudança se deve a criação do Sistema de Seleção Unificada (Sisu). As provas passaram a ser realizadas em dois dias consecutivos (sábado e domingo), com respectivas durações de tempo de $4 \mathrm{~h}$ e 30 minutos e $5 \mathrm{~h}$ e 30 minutos. E a aplicação das provas foi posta para o último trimestre do ano (outubro, novembro ou dezembro) dependendo do calendário de cada ano, sendo antes realizada em meados de agosto (Faro, 2013).

O exame passou por novas mudanças em 2017, porém essas alterações foram postas em uma consulta pública para que os participantes pudessem contribuir com sugestões para o aprimoramento do exame. Algumas das alterações propostas foram: dias de aplicação das provas, ordem de aplicação por áreas do conhecimento e certificação do ensino médio. O Enem de hoje segue as recomendações propostas em 2017, sendo que em 2018, acrescentou mais 30 minutos na prova do segundo domingo, passando de 4 h e 30 minutos para 5 horas. Também na edição de 2020, os participantes puderam optar por provas digitais, fazendo o exame através do computador. Como foi o ano de teste, poderiam ser inscritos até 100 mil estudantes de 15 capitais para a realização da prova. As próximas edições do exame seguirão as mudanças propostas para se adaptarem ao novo Ensino Médio (Santos et al., 2018).

No ambiente escolar, o componente curricular de química apresenta algumas limitações, talvez mais do que nos outros componentes curriculares presentes na área de ciências da natureza. Para Pontes et al. (2008), muitos alunos demonstram dificuldades no aprendizado de química. Na maioria das vezes, não conseguindo perceber o significado ou a importância do que estudam. Entretanto, os métodos da aprendizagem, com o passar dos anos, também sofreram mudanças e se aprimoraram para seguir os avanços culturais e tecnológicos que começaram a surgir. Existem diversos tipos de aprendizagem, consubstanciadas nas mais variadas atividades da vida humana e estão relacionadas ao desenvolvimento da sociedade que, ao longo dos tempos e de acordo com as diferentes culturas, define o que os indivíduos devem saber nas várias áreas do conhecimento humano (Nunes \& Silveira, 2015).

Dessa forma, este estudo tem por objetivo verificar, analisar e discutir as dificuldades encontradas pelos discentes no processo de ensino-aprendizagem da disciplina de química, em conteúdos contemplados na matriz curricular do Enem.

\section{Metodologia}

Em relação a metodologia científica, contida na obra de Lüdke e André (2013), este estudo apresenta uma pesquisa de natureza aplicada, com abordagem quantitativa e exploratória, que tem por finalidade converter em números, métricas, cálculos e percentuais os dados da pesquisa, quantifica-los e convertê-los em informações objetivas. A elaboração do trabalho ocorreu na Escola Pública de Ensino Médio Regular Edite Alcântara Mota, presente na localidade do Pecém - CE, Município de São Gonçalo do Amarante.

O trabalho foi realizado no segundo semestre de 2020 com as turmas de terceiros anos dos turnos da manhã e da tarde. O total de turmas participantes foram quatro, sendo três pertencentes ao turno da manhã e uma ao turno da tarde. Conforme 
informações coletadas na secretaria da escola, a quantidade de alunos matriculados nas quatro turmas correspondeu a 145 alunos. Porém, o estudo não abrangeu todos os alunos, devido à paralisação das aulas presenciais nas escolas em 18 de março de 2020, em decorrência da pandemia da COVID-19.

O momento pandêmico teve e tem como uma de suas medidas o isolamento social. Por esta razão, os Conselhos Estaduais de Educação regulamentaram, em regime especial, as atividades escolares não presenciais. Tendo como ferramenta de suporte os recursos tecnológicos, como 'WhatsApp', 'Aluno Online' (plataforma das Escolas da Rede Pública Estadual) e serviços fornecidos pela plataforma 'Google', como o 'Google Meet' transmitindo em tempo real as aulas remotas e o 'Google Formulário', serviço que disponibiliza realização de teste e avaliações, entre outros recursos existentes. A metodologia para realizar o seguinte trabalho sofreu várias adaptações para se encaixar neste novo cenário. Para Dias et al. (2021), a utilização do 'Google Formulário' como instrumento avaliativo se tornou indispensável neste período pandêmico, mesmo apresentando algumas limitações.

Os discentes foram informados sobre os objetivos deste estudo e informados sobre o Termo de Consentimento Livre e Esclarecido - TCLE, solicitando-lhes sua anuência. Em seguida, foi explicado que durante a coleta de dados seriam omitidos os nomes dos participantes, respeitando a integridade e o sigilo de suas respostas. Posteriormente, foi aplicado um questionário intitulado: 'Teste de Química', envolvendo questões dos conteúdos mais abordados no ENEM, a partir da análise dos sites mencionados na Tabela 1

Tabela 1 - Conteúdos recorrentes no ENEM a partir da análise de sites da Internet.

\begin{tabular}{|c|c|c|}
\hline $\begin{array}{l}\text { TÍTULO DA } \\
\text { MATÉRIA }\end{array}$ & CONTEÚDOS RECORRENTES NO ENEM & LINK \\
\hline $\begin{array}{l}9 \text { assuntos de química que } \\
\text { mais caem no ENEM }\end{array}$ & $\begin{array}{l}\text { Estequiometria - Termoquímica - Radioatividade - } \\
\text { Processos de Oxidação e Redução - Equilíbrio Químico - } \\
\text { pH - Química Orgânica - Estudo de Moléculas - Química } \\
\text { Ambiental }\end{array}$ & $\begin{array}{l}\text { https://prouniversidade.com.br/aulasonline/blog/9- } \\
\text { assuntos-de-quimica-que-mais-caem-no-enem/ }\end{array}$ \\
\hline $\begin{array}{l}\text { Química no ENEM: veja } \\
\text { o que mais cai no exame! }\end{array}$ & $\begin{array}{l}\text { Estudo de moléculas - Química Orgânica - Reações } \\
\text { Inorgânicas - Soluções - Cálculos Estequiométricos - } \\
\text { Eletroquímica - Termoquímica - Poluição Ambiental - } \\
\text { Radioatividade }\end{array}$ & $\begin{array}{l}\text { https://www.stoodi.com.br/blog/quimica/o-que- } \\
\text { mais-cai-de-quimica-no-enem/ }\end{array}$ \\
\hline $\begin{array}{l}\text { Quais os assuntos mais } \\
\text { cobrados em Química no } \\
\text { ENEM. }\end{array}$ & $\begin{array}{l}\text { Ligações Químicas - Reações Orgânicas - Compostos } \\
\text { Orgânicos - Eletroquímica - Estequiometria - Soluções - } \\
\text { Estrutura da Matéria - Equilíbrio Químico - Reações } \\
\text { Inorgânicas - Termoquímica }\end{array}$ & $\begin{array}{l}\text { https://guiadoestudante.abril.com.br/estudo/quais- } \\
\text { os-assuntos-mais-cobrados-de-quimica-no-enem/ }\end{array}$ \\
\hline $\begin{array}{l}\text { Confira o que mais cai em } \\
\text { Química no ENEM e } \\
\text { ainda dicas de como } \\
\text { estudar para essa } \\
\text { disciplina }\end{array}$ & $\begin{array}{l}\text { Química Ambiental - Química Orgânica - Estequiometria - } \\
\text { Química Inorgânica - Separação de Misturas - } \\
\text { Termoquímica - Ligações Químicas - Radioatividade - } \\
\text { Soluções - Bioquímica - Equilíbrio Químico }\end{array}$ & $\begin{array}{l}\text { https://blog.imaginie.com.br/o-que-mais-cai-em- } \\
\text { quimica-no-enem/ }\end{array}$ \\
\hline $\begin{array}{l}\text { Química ENEM: confira } \\
\text { os assuntos que mais } \\
\text { caem e como estudar }\end{array}$ & $\begin{array}{l}\text { Estudo da Matéria - Estrutura Atômica - Tabela Periódica } \\
\text { - Funções Inorgânicas - Relações Numéricas - } \\
\text { Estequiometria e Soluções - Termoquímica - Cinética e } \\
\text { Equilíbrio Químico - Eletroquímica - Química Orgânica }\end{array}$ & $\begin{array}{l}\text { https://descomplica.com.br/tudo-sobre- } \\
\text { enem/novidades/quimica-enem/ }\end{array}$ \\
\hline
\end{tabular}

Fonte: Autores.

A aplicação do questionário, com cinco questões, foi realizada pela ferramenta de formulários do Google (Google Forms), tendo participado de 34 alunos. O teste foi aplicado para direcionar as dificuldades apresentadas pelo aluno, relacionando 
sua aprendizagem durante o período de formação no Ensino Médio.

\section{Resultados e Discussão}

O questionário foi organizado com questões do Enem de edições anteriores e os conteúdos selecionados correspondem aos mais abordados dentro da competência curricular de Química contida na matriz de referência do ENEM, a saber: cálculo estequiométrico; polaridade das ligações químicas; compostos orgânicos; equilíbrio químico e eletroquímica, atribuindo para cada conteúdo uma questão, totalizando cinco questões. O "Teste de Química” foi aplicado com auxílio da ferramenta 'Google formulário', cada aluno limitava-se a responder ao teste apenas uma única vez. Os resultados quanto ao número de acertos por questão estão elencados no Gráfico 1 a seguir.

Gráfico 1 - Quantidade de participantes que acertaram as questões do Teste de Química.

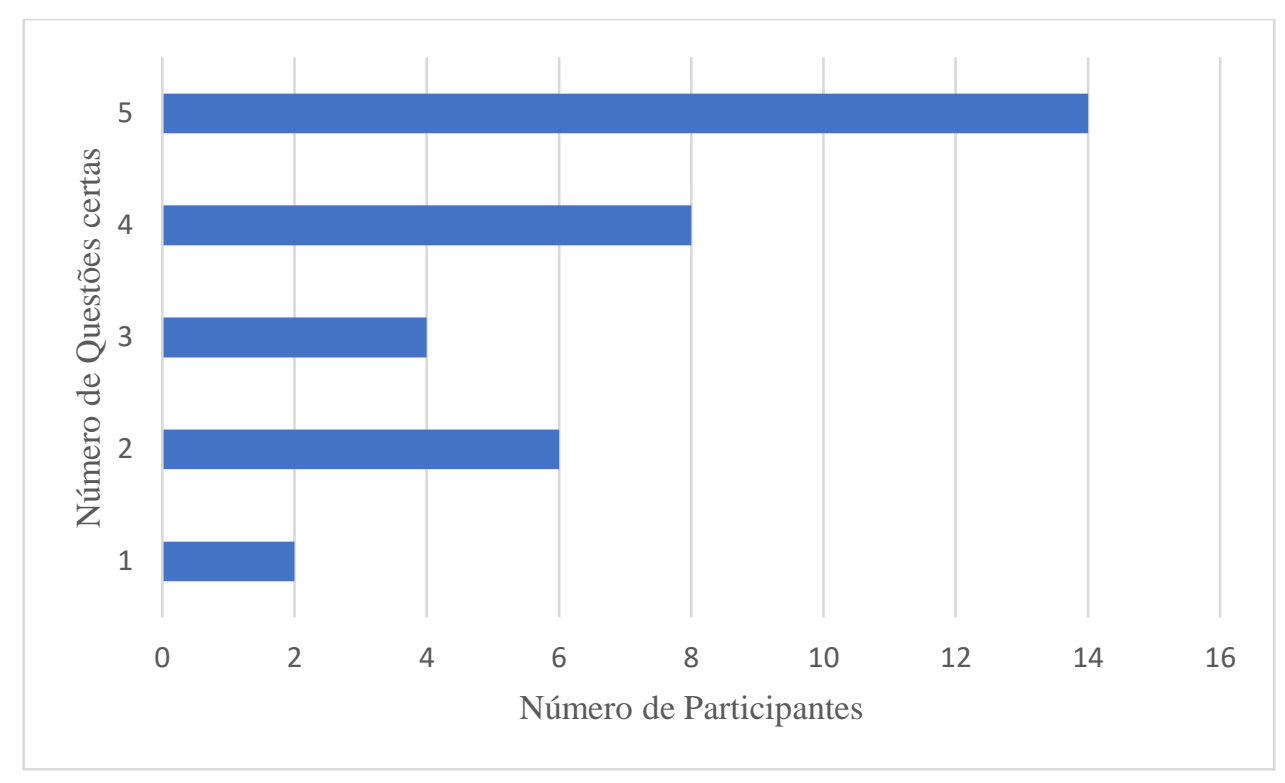

Fonte: Autores.

Uma preocupação sobre a aplicação do questionário de modo remoto, residia na inquietação quanto a veracidade dos resultados, pois os alunos podiam passar o gabarito entre si, como também pesquisar as respostas pela internet ou outras fontes. No entanto, somente $41,2 \%$ dos alunos que realizaram a prova acertaram todas as questões, isso representando um total de 14 alunos, como demonstra o Gráfico 1.

Analisando a quantidades de alunos que acertaram quantidades inferiores ou iguais a três questões, observa-se um percentual de 35,3\%, totalizando 12 alunos. Esses dois resultados são bastante próximos, demonstrando que há baixa probabilidade de o gabarito ter sido compartilhado, como também pode-se inferir que alguns alunos não tiveram interesse de pesquisar sobre as questões, pondo fim a esta preocupação.

O percentual relativo ao desempenho dos alunos pode ser verificado abaixo, na Figura 1. Nela está contida a pergunta utilizada no questionário, bem como os assuntos pertinentes ao conteúdo curricular de química; as competências e habilidades extraídas de cada questão a partir da matriz de referência do ENEM, e o percentual de acertos e erros dos estudantes. 
Figura 1 - Desempenho dos Estudantes no Teste de Química em percentual de acertos/erros e competências e habilidades das questões conforme a matriz de referência do ENEM.

\begin{tabular}{|c|c|c|c|c|c|}
\hline \multirow[t]{2}{*}{$\mathbf{N}^{\mathbf{o}}$} & \multirow[t]{2}{*}{ Questão do ENEM } & \multirow{2}{*}{$\begin{array}{l}\text { Conteúdo } \\
\text { Curricular }\end{array}$} & \multirow{2}{*}{$\begin{array}{l}\text { Competências e Habilidades da } \\
\text { Matriz de Referência do ENEM }\end{array}$} & \multicolumn{2}{|c|}{$\begin{array}{l}\text { Percentual de } \\
\text { Acertos e Erros }\end{array}$} \\
\hline & & & & Acertos & Erros \\
\hline 1 & $\begin{array}{l}\text { O carro flex é uma realidade no Brasil. Estes veículos estão } \\
\text { equipados com motor que tem a capacidade de funcionar com } \\
\text { mais de um tipo de combustível. No entanto, as pessoas que têm } \\
\text { esse tipo de veículo, na hora do abastecimento, têm sempre a } \\
\text { dúvida: álcool ou gasolina? Para avaliar o consumo desses } \\
\text { combustíveis, realizou-se um percurso com um veículo flex, } \\
\text { consumindo } 40 \text { litros de gasolina e no percurso de volta utilizou- } \\
\text { se etanol. Foi considerado o mesmo consumo de energia tanto no } \\
\text { percurso de ida quanto no de volta. O quadro resume alguns } \\
\text { dados aproximados sobre esses combustíveis. O volume de } \\
\text { etanol combustível, em litro, consumido no percurso de volta é } \\
\text { mais próximo de }\end{array}$ & $\begin{array}{c}\text { Cálculo } \\
\text { Estequiomé } \\
\text { trico }\end{array}$ & $\begin{array}{l}\text { Competência de área } 7 \text { - Apropriar-se } \\
\text { de conhecimentos da química para, em } \\
\text { situações problema, interpretar, avaliar } \\
\text { ou planejar intervenções científico } \\
\text { tecnológicas. Habilidade H25: } \\
\text { Caracterizar materiais ou substâncias, } \\
\text { identificando etapas, rendimentos ou } \\
\text { implicações biológicas, sociais, } \\
\text { econômicas ou ambientais de sua } \\
\text { obtenção ou produção. }\end{array}$ & 73,5 & 26,5 \\
\hline 2 & $\begin{array}{l}\text { Uma das atividades mais comuns entre os surfistas é, antes de } \\
\text { entrar com sua prancha mar adentro, passar parafina sobre toda a } \\
\text { superfície do material com a finalidade de melhorar a fixação dos } \\
\text { pés e facilitar as manobras. Tal procedimento é extremamente } \\
\text { relacionado aos conceitos de forças intermoleculares, uma vez } \\
\text { que há diferentes tipos de parafinas, que variam desde a } \\
\text { salinidade do mar até a temperatura das correntes que banham } \\
\text { determinadas praias. Sobre os conceitos de forças } \\
\text { intermoleculares, considerando que a parafina é um composto } \\
\text { praticamente apolar e que a água do mar é composta basicamente } \\
\text { por } \mathrm{H}_{2} \mathrm{O} \text { (polar) e } \mathrm{NaC \ell} \text { (iônico) dissolvido, é correto afirmar que }\end{array}$ & $\begin{array}{l}\text { Forças } \\
\text { Intermolecu } \\
\text { lares e } \\
\text { Polaridade } \\
\text { das } \\
\text { Moléculas e } \\
\text { Ligações } \\
\text { Químicas }\end{array}$ & $\begin{array}{l}\text { Competência de área } \mathbf{5}-\text { Entender } \\
\text { métodos e procedimentos próprios das } \\
\text { ciências naturais e aplicá-los em } \\
\text { diferentes contextos. Habilidade H18: } \\
\text { Relacionar propriedades físicas, } \\
\text { químicas ou biológicas de produtos, } \\
\text { sistemas ou } \\
\text { procedimentos tecnológicos às } \\
\text { finalidades a que se destinam. }\end{array}$ & 82,4 & 17,6 \\
\hline 3 & $\begin{array}{l}\text { As abelhas utilizam a sinalização química para distinguir a } \\
\text { abelha-rainha de uma operária, sendo capazes de reconhecer } \\
\text { diferenças entre moléculas. A rainha produz o sinalizador } \\
\text { químico conhecido como ácido 9-hidroxidec-2-enoico, enquanto } \\
\text { as abelhas-operárias produzem ácido 10-hidroxidec-2-enoico. } \\
\text { Nós podemos distinguir as abelhas-operárias e rainhas por sua } \\
\text { aparência, mas, entre si, elas usam essa sinalização química para } \\
\text { perceber a diferença. Pode-se dizer que veem por meio da } \\
\text { química. LE COUTEUR, R; BURRESON, J. Os botões de } \\
\text { Napoleão: as } 17 \text { moléculas que mudaram a história. Rio de } \\
\text { Janeiro: Jorge Zahar, 2006 (adaptado). As moléculas dos } \\
\text { sinalizadores químicos produzidas pelas abelhas rainha e } \\
\text { operária possuem diferença na }\end{array}$ & $\begin{array}{c}\begin{array}{c}\text { Estrutura } \\
\text { dos }\end{array} \\
\text { Compostos } \\
\text { Orgânicos }\end{array}$ & $\begin{array}{l}\text { Competência de área } 7 \text { - Apropriar-se } \\
\text { de conhecimentos da química para, em } \\
\text { situações problema, interpretar, avaliar } \\
\text { ou planejar intervenções científico } \\
\text { tecnológicas. Habilidade H24 - Utilizar } \\
\text { códigos e nomenclatura da química para } \\
\text { caracterizar materiais, substâncias } \\
\text { ou transformações químicas. }\end{array}$ & 67,6 & 32,4 \\
\hline 4 & $\begin{array}{l}\text { Hipoxia ou mal das alturas consiste na diminuição de oxigênio } \\
\left(\mathrm{O}_{2}\right) \text { no sangue arterial do organismo. Por essa razão, muitos } \\
\text { atletas apresentam mal-estar (dores de cabeça, tontura, falta de ar } \\
\text { etc.) ao praticarem atividade física em altitudes elevadas. Nessas } \\
\text { condições, ocorrerá uma diminuição na concentração de } \\
\text { hemoglobina oxigenada }\left(\mathrm{HbO}_{2}\right) \text {. A alteração da concentração de } \\
\text { hemoglobina oxigenada no sangue ocorre por causa do(a) em } \\
\text { equilíbrio no sangue, conforme a relação: a alteração da } \\
\text { concentração de hemoglobina oxigenada no sangue ocorre por } \\
\text { causa do(a) }\end{array}$ & $\begin{array}{l}\text { Equilíbrio } \\
\text { Químico }\end{array}$ & $\begin{array}{l}\text { Competência de área 4: Compreender } \\
\text { interações entre organismos e ambiente, } \\
\text { em particular aquelas relacionadas à } \\
\text { saúde humana, relacionando } \\
\text { conhecimentos científicos, aspectos } \\
\text { culturais e características individuais. } \\
\text { Habilidade H15: Interpretar modelos e } \\
\text { experimentos para explicar fenômenos } \\
\text { ou processos biológicos em qualquer } \\
\text { nível de organização dos sistemas } \\
\text { biológicos. }\end{array}$ & 76,5 & 23,5 \\
\hline 5 & $\begin{array}{l}\text { O crescimento da produção de energia elétrica ao longo do tempo } \\
\text { tem influenciado decisivamente o progresso da humanidade, mas } \\
\text { também tem criado uma séria preocupação: o prejuízo ao meio } \\
\text { ambiente. Nos próximos anos, uma nova tecnologia de geração } \\
\text { de energia elétrica deverá ganhar espaço: as células a } \\
\text { combustível hidrogênio/oxigênio. Com base no texto e na figura, } \\
\text { a produção de energia elétrica por meio da célula a combustível } \\
\text { hidrogênio/oxigênio diferencia-se dos processos convencionais } \\
\text { porque }\end{array}$ & $\begin{array}{l}\text { Eletroquími } \\
\text { ca }\end{array}$ & $\begin{array}{l}\text { Competência de área } \mathbf{6} \text { - Apropriar-se } \\
\text { de conhecimentos da física para, em } \\
\text { situações problema, interpretar, avaliar } \\
\text { ou planejar intervenções científico } \\
\text { tecnológicas. Habilidade H21: Utilizar } \\
\text { leis físicas e (ou) químicas para } \\
\text { interpretar processos naturais ou } \\
\text { tecnológicos inseridos no contexto da } \\
\text { termodinâmica } \quad \text { e(ou) } \\
\text { eletromagnetismo. }\end{array}$ & 76,5 & 23,5 \\
\hline
\end{tabular}

Fonte: Autores. 
De acordo com a figura, na questão número 1 cerca de $74 \%$ do total de alunos marcou a alternativa correta, referente ao cálculo estequiométrico. A resolução desta questão necessita de conhecimentos prévios relacionados a base matemática: como noções em unidades de medidas de volume e suas transformações; informação para se realizar a conversão de litros para mililitros; como também o uso de regra de três simples. Além disso, entre os conhecimentos químicos explícitos e implícitos estão: estabelecer o entendimento dos cálculos estequiométrico através da relação das gramas dos combustíveis com o calor de combustão deles; conhecer a fórmula da densidade: sendo esta definida como a relação entre a massa de uma substância e o seu volume em uma dada temperatura e pressão.

Muitas razões podem ter levado os alunos a optarem pelo item incorreto. Pode-se destacar a dificuldade na base matemática, sendo esta bastante necessária para a resolução, como também, não terem interpretado o enunciado da questão de modo correto; ou ainda, apresentaram uma real dificuldade no conteúdo de estequiometria, caracterizando-o como complexo.

Resultados semelhantes foram encontrados no trabalho de Rodrigues et al., (2020). Os autores perceberam uma relação interdisciplinar entre os conteúdos de biologia e matemática ao analisarem as provas do ENEM do período de 2010 - 2019. A maioria das questões abordadas nestes anos exigiam dos alunos conhecimentos relacionados a porcentagem, conversão de unidades, razão e proporção, bem como a habilidade de interpretar dados de gráficos e tabelas.

Segundo Meneses e Nuñez (2018), os conteúdos de química quando ministrados com intensa fragmentação e descontextualização, sem a relação com outros conteúdos e com os saberes e as vivências do dia a dia dos alunos, promove o ensino de uma ciência pouco significativa e, na maioria das vezes, difícil de ser realmente compreendida e aplicada pelos discentes. A fragmentação externa promove um ensino carregado de excesso de conteúdo e de conceitos, não facilitando a compreensão da essência da ciência estudada. Deste modo, os discentes não atribuem a Química um caráter de importância nas reações que ocorrem no mundo, e ao funcionamento orgânico do ser vivo, tendem a estereotipá-la como difícil, chata e complicada. As dificuldades de aprendizagem representam todas as perturbações que impedem a normalidade do processo de aprender, qualquer que seja o status cognitivo do sujeito, não permitindo o aproveitamento de suas potencialidades (Rocha \& Vasconcelos, 2016).

Às vezes essa dificuldade é decorrente de uma causa neurológica, apresentando um déficit intelectual ou psicodinâmico, ou às vezes correspondem ao simples modo de como se ensina. Aulas sem dinamismos que não possuem nenhum atrativo, que direcionam o aluno a memorizar, desfavorecem totalmente a construção do saber (Freitas \& Mancini, 2019). Essas dificuldades também podem ser caracterizadas pela desordem ou disfunção no processo de aprender, podendo ser apresentada através dos transtornos na aprendizagem: específicos de aprendizagem; do desenvolvimento das habilidades escolares; transtornos funcionais específicos; problemas de aprendizagem e distúrbios de aprendizagem (Barbosa, 2015). O estudante que se enquadra em algum dos transtornos citados, e sendo este de conhecimento do educador, deve ser trabalhado em sala de aula com uma metodologia que venha a amenizar essa dificuldade e contribuir para com a formação do seu conhecimento.

Na segunda questão, aproximadamente $82 \%$ do total de alunos marcou a alternativa correta, referente à polaridade das ligações químicas. Dominar as diferenças entre substâncias iônicas, metálicas e moleculares contribuem para o resultado correto desta questão. Percebendo que as diferenças entre as substâncias estão relacionadas com as polaridades das ligações que os átomos estabelecem entre si, sendo estas expressas nos seus tipos de ligações, iônicas ou covalentes, esta última se caracterizando como polar ou apolar. Ela também apresentou o melhor resultado de acertos em comparação as outras, mostrando que a maioria dos alunos assimilou o conteúdo de forma positiva. A contextualização presente na questão, também favoreceu para a compreensão dos fatos presentes no seu enunciado, facilitando o entendimento do contexto, contribuindo para o resultado apresentado. Veras et al., (2021) afirmam que a contextualização é benéfica para o processo de ensino-aprendizagem, pois é capaz de abranger conceitos e aplicações da matemática e/ou de outras áreas das ciências da natureza para o cotidiano discente, facilitando a compreensão dos conteúdos envolvidos nestes componentes curriculares. 
Para Marques (2017), a realidade do aluno, o seu cotidiano, as suas emoções influenciam na aprendizagem dos conteúdos dos componentes curriculares. Então, a análise das possíveis dificuldades a serem pontuadas é muito mais complexa do que imaginamos, pois se um desses fatores apresentarem qualquer falha pode induzir de modo negativo na aprendizagem do aluno, e assim contribuir para o fracasso escolar. Existem relatos de alunos que, ao saírem do ensino médio, agem como se pouco soubessem dos conteúdos de química, visto que são incapazes de interpretar fenômenos ou reações químicas presente no cotidiano, a partir do conhecimento ou da leitura científica. Considerando os fenômenos e a literatura pertinente, apesar do seu elevado grau de importância, os alunos demonstram dificuldade em aprendê-los.

Outro ponto de vista quando se fala das dificuldades dos alunos em compreender os conceitos químicos, sempre associamos primeiro com a precariedade de algumas instituições públicas no quesito estrutura física, algumas não possuindo Laboratório de Ciências ou este encontrando-se em estado sucateado, como também, a carência de recursos fornecida à escola e a qualificação dos docentes. Este último se enquadra de forma persistente na realidade da educação em química, na qual boa parte dos docentes que se encontram em sala de aula, apresentam na maioria das vezes outra formação, não sendo este qualificado para lecionar química, e do mesmo modo, o aluno tende a não compreender a importância da química perante a sociedade, pois este componente curricular constrói uma visão crítica e contribui como formadora de opinião. Santos et al., (2013) afirmam que alunos e professores não compreendem os verdadeiros motivos para estudar e ensinar Química, e ainda, parte da motivação parece estar relacionada com a futura profissão a ser seguida.

Na terceira questão, 68\% do total de alunos marcou a alternativa correta, referente a compostos orgânicos. Esta questão abrange um entendimento em vários pontos da química orgânica, como: possuir discernimento em funções oxigenadas e nomenclatura; saber relacionar os nomes dos compostos a função do ácido carboxílico e a presença da hidroxila na cadeia principal, observando-se a mudança em sua posição, apresentando uma distinção nas fórmulas estruturais dos compostos citados na questão.

Examinando o resultado, o item incorreto mais marcado foi fórmula molecular, isso pode ter ocorrido por uma desatenção dos alunos, pois esta resposta é bastante parecida com a correta; ou o aluno não apresenta o conhecimento que vem a distinguir essas duas fórmulas. Para a melhoria do processo de ensino-aprendizagem em química, é necessário que o docente adote as correntes pedagógicas, a partir do diagnóstico da sua turma. Estas ações tornam-se úteis para a compreensão do pensamento instrutivo no processo de aprendizagem, servindo de grande auxílio para o professor e para o aluno, durante a trajetória do processo educacional (Nunes \& Silveira, 2015).

O construtivismo, tendência pedagógica utilizada por muitos docentes, aborda a epistemologia genética elaborada por Jean Piaget. Esta concepção pedagógica afirma que só podemos conhecer algo por meio de interações com o ambiente, num intercâmbio de trocas recíprocas sujeito-meio. Sendo a evolução do conhecimento um processo contínuo, construído a partir da interação ativa. A aprendizagem, em Piaget, é um processo complexo, que requer elaboração interna de um modo ativo e singular, não sendo um ato de incorporação passiva e mecânica (Paixão Junior \& Pereira Junior, 2016).

Já para a corrente socioconstrutivista de Vygotsky o aluno deve estar inserido em um meio social e sua aprendizagem se iniciará através das informações produzidas por esse ambiente no qual está inserido, para em seguida, interiorizá-las. Partindo do ponto de vista que a aprendizagem ocorre por meio do relacionamento entre aluno-professor e aluno-aluno. Na abordagem Vygotskyana, o homem é visto como alguém que transforma e é transformado nas relações que acontecem em uma determinada cultura. O que ocorre não é uma somatória entre fatores inatos e adquiridos e sim uma interação dialética que se dá, desde o nascimento, entre o ser humano e o meio social e cultural em que se insere. Assim, é possível constatar que o ponto de vista de Vygotsky é que o desenvolvimento humano é compreendido não como a decorrência de fatores isolados que amadurecem, nem tampouco de fatores ambientais que agem sobre o organismo controlando seu comportamento, mas sim como produto de trocas recíprocas, que se estabelecem durante toda a vida, entre indivíduo e meio, cada aspecto influindo sobre o outro (Neves \& 
Damiani, 2006)

O meio no qual o ser humano está inserido, sempre terá uma contribuição para a sua formação e geração de conhecimento. Pavlov e Skinner afirmavam que o comportamento humano sofre uma influência dos estímulos fornecidos pelo meio. Essa corrente da psicologia conhecida como comportamentalismo ou Behaviorismo, enfoca que o comportamento do indivíduo é moldado dependendo do estímulo a este fornecido, simplesmente o organismo apresentará reações que serão desencadeadas pelos estímulos externos. As respostas advindas dos estímulos externos são consequências dos nossos comportamentos, são essas respostas que postulam nossas ações como o mais adequado ou, ao menos em parte delas, influenciam a fundação do que se chama teoria do comportamentalismo, campo do conhecimento conhecido como análise do comportamento humano (Andrade et al., 2019).

O aspecto proposto por Pavlov era voltado para a conexão entre estímulo e resposta, já o Skinner não se preocupava com os estímulos que provocam a resposta, mas sim com o que ocorre após a resposta, ou seja, o importante para ele está entre resposta e reforço, caso o resultado fosse indesejado haveria punição. Essas teorias têm em comum a existência de uma interação entre o sujeito-meio, podendo a aprendizagem partir de ações presentes do cotidiano, no qual aluno aprende através da observação dessas ações, ou as vivenciando. Então, a prática pedagógica baseada na utilização de fatos do dia a dia para ensinar conteúdos científicos pode caracterizar o cotidiano em um papel secundário, ou seja, este servindo como mera exemplificação ou ilustração para ensinar conhecimentos químicos (Wartha et al., 2013)

Para auxiliar no processo de ensino/aprendizagem Ausebel, defensor do construtivismo como Piaget, apresenta a teoria de aprendizagem significativa que foca no aluno, como um sujeito, que possui um conhecimento prévio, já adquirido, para assim, alcançar uma aprendizagem através de informações novas. Neste contexto, o estudante já possui uma base de conhecimento, apresentando um interesse e uma abertura em adquirir algo novo, sendo isto um estímulo no ato de querer aprender do discente.

$\mathrm{Na}$ quarta questão,77\% do total de alunos marcou a alternativa correta, referente a equilíbrio químico. Neste conteúdo, o ponto relevante exigido para conseguir resolver a questão está em compreender os fatores que alteram o estado de equilíbrio focando no efeito da pressão. Como a questão cita o "mal das alturas", sabe-se que em condições bastante elevadas a pressão atmosférica baixa, tornando o ar rarefeito, ocasionando uma diminuição da pressão parcial de oxigênio no sangue. Percebe-se também que esta questão envolve conhecimentos associados a sistemas biológicos que evidenciam a importância da construção de um currículo escolar que necessita ser abordado de forma interdisciplinar e que valorize os conhecimentos prévios trazidos pelos discentes.

De acordo com Oliveira e Cuenca (2016), a aplicação da teoria de Ausubel permite a aprendizagem de conceitos químicos considerando a participação do aprendiz na construção de material potencialmente significativo e seus conhecimentos prévios como essenciais para a produção de novos conhecimentos. Os autores afirmam que a utilização desta estratégia de aprendizagem obteve um melhor rendimento nas turmas em que foram submetidas e estimulou o engajamento dos alunos no processo de construção do conhecimento, mesmo diante de situações as quais não estavam acostumados, dada a habitual falta de oportunidade de discussão ocorrida nas aulas tradicionais.

Outro modelo que consegue representar e favorecer o processo educacional em química foi apresentado por Charles Sanders Peirce e relacionava objetos e pensamentos, aproveitando reflexões adquiridas em outras áreas para construir o entendimento da teoria da semiótica, onde o estudo se baseia em signos. Parecendo ser o principal e único modelo que discute a questão das representações no ensino de Química, não encontrando qualquer divergência sobre o modelo dos três diferentes níveis de representação, na literatura sobre educação química (Wartha et al., 2013). Sendo que a perspectiva da semiótica Peirceana é vista como um conteúdo apreendido pelos sentidos, pela memória, pela imaginação, pelo pensamento, o que a caracteriza como a 'Teoria geral dos signos' ou 'Teoria geral das representações'.

Diante disto, todo o conhecimento consiste em descobrir algo sobre alguma coisa, ou seja, o conhecimento se estabelece 
quando os seres humanos buscam respostas aos seus questionamentos e inquietações. Nesse sentido, é preciso compreender como se estabelece o conhecimento dos estudantes, o qual está diretamente relacionado com as teorias de aprendizagem que o professor concebe. Uma parcela dos estudantes não consegue associar algumas situações ou ações presentes no seu cotidiano com os fenômenos físico-químicos apresentados. Apontando uma dificuldade em realizar a conexão entre o que vivenciam no dia a dia, com os conteúdos abordados em sala de aula. Manifestando algum problema cognitivo na assimilação dos conceitos e conteúdos propostos no processo de ensino e aprendizagem da química (Leão \& Dutra, 2018).

Na última questão, aproximadamente $77 \%$ do total de alunos marcou a alternativa correta, referente à eletroquímica. O conceito deste conteúdo refere-se a um fenômeno onde ocorre a transformação de energia química em energia elétrica, ou o contrário, sendo esta oriunda da transferência de elétrons, envolvendo reações de oxirredução. A resolução da questão, necessita também do conhecimento sobre célula a combustível favorecendo na escolha do item correto, pois compreende que a energia liberada nas reações de combustão se converte em energia elétrica, exibindo ao final de sua reação a produção de água, praticamente não gerando gases poluentes.

Para Rocha e Vasconcelos (2016), a dificuldade de assimilação dos conteúdos da área de Ciências da Natureza e o antagonismo no processo de aprendizagem dos conteúdos químicos, encontra-se vinculado às características da personalidade dos estudantes, bem como aos seus anseios e desejos. O ensino dos conteúdos do currículo escolar desvinculados das emoç̃os dos estudantes promove uma aprendizagem que não lhes interessa ou não faz sentido para as suas existências, sendo nesse contexto, muito provável que surja a recusa em aprender. Assim, apresentar as dificuldades para aprender pode ser uma reação saudável do sujeito, especialmente quando esta carga vem carregada de valores e atitudes sem sentido ou significado para ele, é o que muitas vezes ocorre no ensino de Química.

O conceito de dificuldade de aprendizagem para cada teórico depende do fator que este considera importante, mas no contexto geral, não denota distinção. Segundo Kauark e Silva (2008) esta dificuldade pode ser expressa quando a aprendizagem foge às expectativas do professor, restringindo a uma determinada limitação do saber por parte do aluno. Quando este não alcança e não desenvolve os padrões previstos em tempos esperados a referida aprendizagem.

Com isso, o papel do professor compreende superar as problemáticas que surgirem, em prol do processo de ensino e aprendizagem dos alunos, motivando-os a terem interesse pelo componente curricular através de aulas dinâmicas, incentivandoos a criar seu próprio ponto de vista por meio do raciocínio, guiando e favorecendo a percepção do aluno aos conceitos químicos empregados na atual sociedade tecnológica.

Segundo o que foi proposto na Lei de Diretrizes e Bases da Educação Nacional - LDB No 9.394/1996, a educação abrange os processos formativos que se desenvolvem na vida familiar, na convivência humana, no trabalho, nas instituições de ensino e pesquisa, nos movimentos sociais e organizações da sociedade civil e nas manifestações culturais (BRASIL, 1996). Como citado na lei, à disciplina da química está inserida dentro deste contexto contribuindo na formação de um cidadão consciente do seu papel social e que possui pensamento crítico, capaz de compreender e solucionar problemas, sendo este um estudante ativo e protagonista no seu processo de aprendizagem.

Os procedimentos metodológicos utilizados para a formação do indivíduo se entrelaçam com valores e atitudes socioculturais, visando alcançar a compreensão da natureza e sua transformação, como as ações dos homens, analisando o grande universo de interações presentes entre o meio e o sujeito. Conforme afirma Marques (2017), o conhecimento químico constituise como importante ferramenta de capacitação para a cidadania, tornando os indivíduos cidadãos conscientes e críticos capazes de opinar e modificar os fatos e acontecimentos importantes do dia a dia.

Deste modo, o ensino de química tem um papel importante na formação discente, pois esta ciência se encontra presente constantemente na sociedade, fazendo parte do cotidiano do aluno. Exigindo do estudante os conhecimentos básicos para interagir com as tecnologias que estão ao seu alcance. Com isso, um Ensino Médio significativo exige que a Química assuma 
seu verdadeiro valor cultural, enquanto instrumento fundamental numa educação humana de qualidade, constituindo-se num meio coadjuvante no conhecimento do universo, na interpretação do mundo e na responsabilidade ativa da realidade em que se vive (Lima, 2012).

\section{Conclusão}

O conhecimento básico em matemática e a dificuldade de interpretar as questões são apontados como as principais dificuldades no processo de aprendizagem em química, sendo este conhecimento importante em todos os componentes curriculares. Assim, a complexidade dos conteúdos e a falta de contextualização dos conteúdos relativos à química, levam o aluno a falta de compreensão, pois ele não consegue relacionar o saber de sala de aula com situações vivenciadas.

No teste com questões do Enem destacou-se o conteúdo Polaridade das Ligações Químicas, tendo o melhor resultado de acertos em comparação as outras questões, deduzindo-se que a maioria dos alunos assimilou o conteúdo de forma positiva. Compostos orgânicos e cálculos estequiométricos apresentaram menores resultados presumindo que a maior dificuldade se encontra em relacionar conteúdos com cálculos que exijam interpretação, bem como identificar as funções oxigenadas e entender sua estrutura e nomenclatura, sendo estas informações necessárias para a resolução de algumas questões presentes na avaliação do ENEM.

Desta forma, conclui-se que é relevante a necessidade de uma abordagem dos conteúdos de química de forma interdisciplinar e contextualizada, de modo que os alunos possam relacionar as vivências de sala de aula com o seu dia a dia; e que estudos futuros possam fornecer outras metodologias para trabalhar os conteúdos de cálculo estequiométrico e compostos orgânicos, seja por meio da utilização das tecnologias digitais da informação e comunicação - TDIC's, ou através da incorporação de novas abordagens em educação na formação inicial e continuada dos professores.

\section{Referências}

Andrade, D. E. da S., Neto, A. F. P. P., Oliveira, C. A. de, \& Brito, J. A. (2019). Comportamentalismo, Cognitivismo e Humanismo : uma revisão de literatura. Revista Semiárido de Visu, 7(2), 222-241. https://doi.org/00.0000/0000-0000.2018x0y0z0

Barbosa, M. de B. (2015). Dificuldades de aprendizagem no contexto escolar: perspectivas para sua compreensão e superação. [Trabalho de Conclusão do Curso, Universidade Estadual Paulista Júlio de Mesquita Filho]. Biblioteca de Teses e Dissertações: https://repositorio.unesp.br/handle/11449/128232.

Belo, T. N., Leite, L. B. P., \& Meotti, P. R. M. (2019). As dificuldades de aprendizagem de química: um estudo feito com alunos da Universidade Federal do Amazonas. Scientia Naturalis, 1(3), 1-9.

BRASIL, M. da E. (1996). LDB: Lei de diretrizes e bases da educação nacional. In Senado Federal. http://portal.mec.gov.br/seesp/arquivos/pdf/lei9394_ldbn1.pdf

da Silveira, F. L., Barbosa, M. C. B., \& da Silva, R. (2015). Exame nacional do ensino Médio (ENEM): Uma análise crítica. Revista Brasileira de Ensino de Fisica, 37(1), 1-5. https://doi.org/10.1590/S1806-11173710001

Dias, G. N., Silva, P. R. S. da;, Pamplona, V. M. S., Araújo, J. C. O., Barbosa, E. da S., Lobato, F. da S., Souza Júnior, J. C. B. de;, Silva Junior, W. L. P. da;, Vogado, G. E. R., Barreto, W. D. L., Leal, A. P. I. P., Silva Junior, A. F., \& Pinto, G. P. (2021). A utilização do Formulários Google como ferramenta de avaliação no processo de ensino e aprendizagem em tempos de pandemia de Covid-19: um estudo em uma escola de educação básica. Research, Society and Development, 10(4), e44910414180. https://doi.org/10.33448/rsd-v10i4.14180

Faro, P. R. O. de. (2013). Convergências e divergências entre o desempenho no ENEM e no Vestibular da UnB. [Trabalho de Conclusão do Curso, Universidade de Brasília. Biblioteca de Teses e Dissertações: https://bdm.unb.br/handle/10483/6364.

Figueiredo, G., Nobre, I., \& Passos, M. L. S. (2015). Tecnologias computacionais na educação: desafios na prática docente. Anais do Workshop de Informática na Escola. Maceió, AL, Brasil, 21. https://doi.org/10.5753/cbie.wie.2015.127

Freitas, J. L. A., \& Mancini, K. C. (2019). Contribuições da ludicidade no processo de ensino e aprendizagem de conhecimentos científicos e culturais. KiriKerê: Pesquisa em Ensino, 7, 104-122.

G1. (2020). Resultado do ENEM 2019 é divulgado pelo INEP. G1 Educação. https://g1.globo.com/educacao/enem/2019/noticia/2020/01/17/notas-do-enem2019-sao-divulgadas-pelo-inep.ghtml

Kauark, F. da S., \& Silva, V. A. dos S. (2008). Dificuldades de aprendizagem nas séries iniciais do ensino fundamental e ações psico \& pedagógicas. Revista Psicopedagogia, 25(78), 264-270. http://pepsic.bvsalud.org/scielo.php?pid=S0103-84862008000300009\&script=sci_abstract\&tlng=es 
Leão, M. F., \& Dutra, M. M. (2018). Influências do comportamentalismo , cognitivismo e humanismo na prática pedagógica de alguns professores de ciências da região do Baixo Araguaia (MT). Educação em Debate, 40(76), 146-162.

Lima, O. G. D. E. (2012). Do período colonial aos nossos dias: uma breve história do ensino de química no Brasil. Revista Espaço Acadêmico, 12(140), 71-79.

Lüdke, M., \& André, M. E. D. A. (2013). Pesquisas em educação: uma abordagem qualitativa (2ª ed). Rio de Janeiro, RJ: Editora Pedagógica e Universitária.

Marques, H. da S. (2017). Aspectos qualitativos nas transformações químicas: um olhar sobre as dificuldades de aprendizagem de alunos do ensino médio na perspectiva Bachelardiana. [Dissertação de Mestrado, Programa de Pós-Graduação em Ensino de Ciências e Matemática, Universidade Federal do Amazonas. Biblioteca de Teses e Dissertações: https://tede.ufam.edu.br/handle/tede/6576.

Meneses, F. M. G. de, \& Nuñez, I. B. (2018). Erros e dificuldades de aprendizagem de estudantes do ensino médio na interpretação da reação química como um sistema complexo. Ciência \& Educação (Bauru), 24(1), 175-190. https://doi.org/10.1590/1516-731320180010012

Neves, R. de A., \& Damiani, M. F. (2006). Vygotsky e as teorias da aprendizagem. UNIrevista, 1(2), 1-10. http://bdtccs.furg.br:8080/handle/1/3453

Nunes, A. I. B. L., \& Silveira, R. do N. (2015). Psicologia da Aprendizagem (3 ${ }^{\mathrm{a}}$ ed.). Fortaleza, CE: Editora da Universidade Estadual do Ceará - EdUECE.

Oliveira, J. C. de, \& Cuenca, M. E. (2016). A Teoria de Aprendizagem Significativa de Ausubel e a (Re)Significação de Conceitos Químicos. In Encontro Nacional de Ensino de Química. Universidade Federal de Santa Catarina. Florianópolis, SC, Brasil, 21. http://www.eneq2016.ufsc.br/anais/resumos/R03181.pdf

Paixão Junior, V. G., \& Pereira Junior, A. (2016). Transgênicos: uma questão bioética. Segurança Alimentar e Nutricional, 23(14), 1041. https://doi.org/10.20396/san.v23i0.8635626

Pizarro, M. V., \& Lopes Junior, J. (2017). Os sistemas de avaliação em larga escala e seus resultados: o PISA e suas possíveis implicações para o ensino de Ciências. Ensaio Pesquisa em educação em Ciências (Belo Horizonte), 19(0), 1-24. https://doi.org/10.1590/1983-21172017190119

Pontes, A. N., Serrão, C. R. G., de Freitas, C. K. A., dos Santos, D. C. P., \& Batalha, S. S. A. (2008). O ensino de química no nível médio: um olhar a respeito da motivação. XIV Encontro Nacional de Ensino de Química, Unico(Ic), 1-10.

Rodrigues, E. G., Oliveira, R. M. de;, Braga, J. dos S., Reis, L. E. M. dos;, Martins, J. da S. C., \& Coimbra Filho, S. (2020). Qual é a relação entre a matemática e a biologia no ENEM? uma análise das provas de 2010 a 2019. Research, Society and Development, 9(11), e78691110301. https://doi.org/10.33448/rsdv9i11.10301

Rocha, J. S., \& Vasconcelos, T. C. (2016). Dificuldades de aprendizagem no ensino de química: algumas reflexões. In Encontro Nacional de Ensino de Química. Universidade Federal de Santa Catarina. Florianópolis, SC, Brasil, 18. https://www.eneq2016.ufsc.br/anais/resumos/R0145-2.pdf.

Santos, A. O., Silva, R. P., Andrade, D., \& Lima, J. P. M. (2013). Dificuldades e motivações de aprendizagem em Química de alunos do ensino médio investigadas em ações do (PIBID/UFS/Química). Scientia Plena, 9(7), 1-6. www.scientiaplena.org.br

Santos, J. M. C. T., Souza, F. das C. S., \& Silva, F. J. B. da. (2018). Exame Nacional do Ensino Médio: considerações sobre a influência do ENEM na produção do currículo de História. História \& Ensino, 24(1), 111. https://doi.org/10.5433/2238-3018.2018v24n1p111

Saviani, D. (2011). Formação de professores no Brasil: dilemas e perspectivas. Poíesis Pedagógica, 9(1), 7-19. https://doi.org/10.5216/rpp.v9i1.15667

Silva, D. C. (2020). Desenvolvimento de um aplicativo de auxílio na preparação em Matemática para o ENEM. Universidade Federal de Campina Grande.

Veras, W. S., Ferreira, L. de A., Sousa, P. S. de A., Carvalho, H. da C., Rodrigues, M. G., Vieira, T. B. dos S., Oliveira, R. E. G., Alves, M. J. P., Ayala, K. N. R., Silva, T. B. L. da, Araujo, J. C. de, Siqueira, F. J. G., \& Vieira Júnior, R. P. M. (2021). Exame Nacional do Ensino Médio (ENEM): conteúdo matemático mais abordado e suas dificuldades. Research, Society and Development, 10(6), e51610616041. https://doi.org/10.33448/rsd-v10i6.16041

Wartha, E. J., Silva, E. L. da, \& Bejarano, R. R. (2013). Cotidiano e contextualização no ensino de Química. Química Nova na Escola, 35(2), 84-91. 